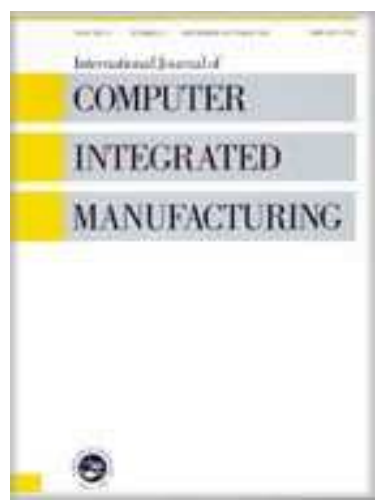

\title{
An End-of-Life Decision Support Tool for Product Recovery Considerations in the Footwear Industry
}

\begin{tabular}{|c|c|}
\hline Journal: & International Journal of Computer Integrated Manufacturing \\
\hline Manuscript ID: & TCIM-2006-IJCIM-0146.R1 \\
\hline Manuscript Type: & Original Manuscript \\
\hline $\begin{array}{r}\text { Date Submitted by the } \\
\text { Author: }\end{array}$ & 18-Apr-2007 \\
\hline Complete List of Authors: & $\begin{array}{l}\text { Staikos, Theodoros; Loughborough University, Wolfson School of } \\
\text { Mechanical and Manufacturing Engineering } \\
\text { Rahimifard, S; Loughborough University, Wolfson School of } \\
\text { Mechanical and Manufacturing Engineering }\end{array}$ \\
\hline Keywords: & SUSTAINABLE DEVELOPMENT, MULTI-CRITERIA DECISION MAKING \\
\hline Keywords (user): & Shoe Recycling, End-of-Life Management \\
\hline
\end{tabular}

\section{scholarONE" \\ Manuscript Central}




\title{
An End-of-Life Decision Support Tool for Product Recovery Considerations in the Footwear Industry
}

\author{
Theodoros Staikos* and Shahin Rahimifard \\ Centre for Sustainable Manufacturing and Reuse/Recycling Technologies (SMART) \\ Wolfson School of Mechanical and Manufacturing Engineering, Loughborough University, UK \\ *T.Staikos@lboro.ac.uk
}

\begin{abstract}
The footwear industry is a manufacturing sector which utilises a wide variety of materials and processes to produce a range of distinctly different products, from sandals to more specialised footwear. Currently, more than 19 billion pairs of shoes are produced worldwide every year. This creates a large waste stream at the end of the functional life of shoes, which are often being disposed in landfills. Producer responsibility concerns and forthcoming legislations as well as increasingly environmental consumer demands expected to challenge the way the global footwear industry is dealing with its end-of-life products. This paper highlights the potential benefits of developing a footwear product recovery methodology and an associated software tool to support decisionmaking regarding the determination of the most suitable (in environmental, economic and social-technical terms) manner in which to treat post-consumer shoe waste. Such methodology in addition to supporting design and material selection processes could also provide benchmark information for the selection of the best end-of-life practise for a selected range of different shoe types. The paper concludes by providing a computational viewpoint of an end-of-life shoe recovery decision support tool.
\end{abstract}


Keywords: Shoe Recycling, Footwear Industry, End-of-Life Management, Decision-Support

\section{Introduction}

Unsustainable consumption and production patterns in the developed world have led to an increased generation of waste over many decades. Although local and national authorities, governmental agencies, manufacturers and the general public have come to recognise the importance of controlling waste at source, total waste elimination is not feasible. There will always be some waste that cannot be prevented at source and so need to be treated at the end of its functional life. Considering the amount of end-of-life (EoL) waste generated every year, understanding and developing methods for end-of-life management are a major part of the overall waste management concern.

The footwear industry over the last 20 years has placed significant effort in improving energy and material efficiency, as well as eliminating the use of hazardous materials during the production phase. However, the environmental gains and energy efficiency made in production are being overtaken by the considerable increase in the demand for footwear products. Several billions of shoes are consumed each year worldwide and many end up in landfills when their functional life has ended. Moreover, the useful life of shoes is relatively short and progressively decreasing as a result of rapid market changes and consumer fashion trends. This creates a large waste stream of worn and discarded shoes. Producer-responsibility issues and forthcoming environmental legislations, as well as increasingly environmental consumer demands, are 
expected to challenge the way the footwear industry deals with its EoL products.

This paper has proposed a footwear product recovery methodology together with an associated software tool to support the decision-making process regarding the determination of the most appropriate end-of-life management option for post-consumer shoes. The initial part of the paper provides a review of materials, processes, styles and types of shoes, which is needed in order to construct alternative end-of-life scenarios. The latter sections present the footwear product recovery methodology and provide a computational viewpoint of the proposed software tool for decision support.

\section{Review of Shoe Manufacturing and Materials}

In any product recovery and recycling application, there are a number of alternative options with different environmental impacts, economic values and social-technical requirements. There is, therefore, a need for a end-of-life decision making process to evaluate these factors in order to identify the best alternative option. However, the value of the results obtained through the decision making process rests in the quality of information entered by the user in the first place. Therefore, before considering these issues in further details it is important to first consider the materials and processes used to make shoes. Based on these background information regarding materials, processes, styles and types of shoes, the footwear product recovery methodology has been developed, as described in Section 4. 
Although there are many different styles and categories of shoes, most of them can be described as having a subset of parts and components that are generally common to all type of shoes. In this context, the basic parts of a shoe can be grouped broadly into three categories (Clarks 1976):

- The Upper, which includes all parts of the shoe above the sole, such as vamp and quarters, that are stitched or joined together to become a unit and then attached to the insole and outsole of the shoe.

- The Lower, which refers to the whole bottom of a shoe but not the upper including the insole, the sole and the outsole of the shoe.

- The Grindery, which includes items that are incorporated into the shoe and do not belong either to the Upper or the Lower part of the shoe such as toe puff, stiffener materials and eyelets.

Some of the major parts and components of a men's formal shoe are depicted in Figure 1.

Figure 1: Major Parts and Components of a Men's Formal Shoe (Rossi 2000)

Alternatively, shoes can be divided using a supply or demand point of view. From the supply point of view, shoes can be subdivided by upper material, for example rubber/plastic, leather and textile-based shoes. On the other hand from the demand point of view, shoes can be divided by activity, for example sports, casual, formal and outdoor shoes. Other categorisations can also be made based on age and gender (i.e. men's, women's and children's). For the purpose 
of this research, footwear products have been categorised into six different types based on their purpose of use:

- Men's formal shoes

- Men's casual shoes

- Women's court shoes

- Women's fashion shoes

- Children's shoes

- Adult sports trainer shoes

Table 1 presents the basic shoe types and the most commonly used materials in their manufacture. Upper components, shoe soles and grindery items are presented according to their material of choice.

Table 1: Component Breakdown of Different Shoe Types

\subsection{Shoe Manufacturing}

The production of footwear starts with the supply of materials. These materials include both raw materials (such as leather) and semi-finished products and components. These materials need to be inspected and modified in order to meet the quality requirements of the footwear industry. Often upper, lower and grindery components are manufactured separately by using different construction methods. Cutting, machining and pre-stitching operations are applied in order to fabricate these components. The next phase of manufacturing is the assembly of the components into finished products. The 
completed upper and lower parts are united using different assembling techniques. Usually the upper is stretched over the last (a fixture which represents the shape of the foot) and attached at the bottom part of the shoe in a process called lasting. There are typically three major assembling techniques used by the footwear industry (Harvey 1982):

- Cementing, where the upper and lower part are assembled using adhesives

- Injection, where the sole material is injected directly to the upper part of the shoe

- Stitching, where the upper and lower part are assembled together with threads.

- Finally, finishing processes determined by the materials that have been used during the manufacturing process. Usually leather materials are stained, polished and waxed before being tagged and delivered to the market.

\subsection{Shoe Materials}

Leather, synthetic materials, rubber and textile materials are counted among the most commonly used materials in shoe manufacturing. These materials differ not only in their appearance but also in their physical qualities, their service life, the different treatment needs as well as their recycling and recovery options at the end of their useful life. According to Weib (1999) there are around 40 different materials used in the manufacturing of a shoe. Figure 2 represents the average composition of a typical shoe which has been measured after grinding. 
Figure 2 : Material Composition in Average Shoe (\%wt) (Weib 1999)

Leather has ideal characteristics for use in the upper part of shoes, is soft with very good absorption ability and able to adjust to the individual shape of the foot. However, leather is a natural material made from animal hides and therefore there is a limited and variable supply depending on stock levels in the meat industry of which hides are a by-product. For this reason, synthetic materials that are designed to look or function like leather have been developed such as fabrics coated with Poly Vinyl Chloride (PVC) and Polyurethane (PU). Leather has also been largely superseded by other materials in the lower part of shoes such as rubber or plastics. In the 1950's only four materials were used as soling materials namely leather, rubber, vulcanised rubber and resin rubber (World Footwear 2005). Since then the choice has been extended to include a number of different plastics and polymers such as PVC, TR, EVA etc. Polymeric and plastic materials currently dominate the production of shoe soles, outsoles and insoles, especially thermoplastic materials and rubbers. Table 2 presents the percentage of the major materials used in the construction of lower parts in shoes.

Table 2: Use of Soling Materials in Shoes (Wilson et al. 1997)

Finally, grindery components include items that are incorporated into the shoe and do not belong to the upper or the lower part of the shoe. These items could be made by a variety of materials depending on their purpose of use. Toe puffs can be made of rubber or thermoplastic resins, stiffener components from leather, EVA and polyester while shank and eyelets can be made of metal 
(carbon steel). Finally, the heel of the shoe is usually made of Polystyrene (PS), Acrylonitrile Butadiene Styrene (ABS), or wood (Harvey 1982).

\section{Magnitude of Shoe Waste Problem}

Worldwide footwear production and consumption has been doubled every 20 years, from 2.5 billion pairs in 1950 to more than 19 billion pairs of shoes in 2006 (World Footwear 2007). In the European Union, footwear consumption has been increased by $22 \%$ from 2002 to 2005 to reach 2.3 billion pairs of shoes (EC 2006). Additionally, the worldwide per capita consumption of footwear has also been considerably increased, from 1 pair of shoes for every person in the world in 1950 to almost 2.6 pair of shoes in 2005 . However, shoe consumption differs significantly per country. Although China has the highest footwear consumption in the world, the United States is the country with the highest per capita shoe consumption, since each inhabitant purchase an average of 6.9 pairs of shoes every year (AAfA 2006). At the other extreme, in the less developed countries, the per capita shoe consumption is 0.6 pairs for India and 0.5 pairs of shoes for Vietnam (all types of shoes included) (SATRA 2003). Figure 3 presents the overall shoe consumption as well as the per capita shoe consumption in a number of different countries.

Figure 3: Per Capita Footwear Consumption in Different Countries (EC 2006, AAfA 2006, SATRA

2003, CBI 2004)

In the UK, more than 320 million pairs of shoes are consumed every year (SATRA 2003). It is estimated that the waste amount arising from postconsumer shoes in the UK could reach 165,000 tonnes per year. A Department 
of Trade and Industry (DTI) study has estimated that the total arising of textile waste is between 550,000 and 900,000 tonnes per year in the UK, while the amount of textile waste reused or recycled annually is estimated to be 250,000 tonnes (ERM 2006). Based on the same study, about $9 \%$ of all recovered postconsumer textiles are sold as second-hand shoes. This means that around 22,500 tonnes of post-consumer shoes are collected in the UK each year for direct reuse in less developed counties. Such reuse schemes are mainly supported by charitable organisations such as the Salvation Army Trading Company (SATCOL ${ }^{\mathrm{TM}}$ ), Oxfam ${ }^{\mathrm{TM}}$ and others in collaboration with local authorities and municipalities. SATCOL ${ }^{\mathrm{TM}}$ alone with its 2,300 banks, door-todoor collections and donations, has managed to collect around 971 tonnes of worn or unwanted shoes during the year 2000-2001 (Woolridge et al. 2006). However, approximately $10 \%$ of the collected shoes are not suitable for direct reuse due to their condition and, consequently end up in landfills (Barry 2006). Based on this estimations, approximately $12 \%(20,250$ tonnes $)$ of postconsumer shoes in the UK are collected and re-distributed as second hand shoes while the rest ( $88 \%$ or 145,200 tonnes) are disposed in landfills.

The standard practice of dumping waste in landfills has led to soil, surface and groundwater contamination. Landfill sites can result in serious environmental pollution of groundwater and rivers, due to landfill leachate ${ }^{1}$. Furthermore, landfill space is becoming extremely limited, while the number of landfill sites in the European Union has considerable decreased over the last years. In early 90's, in Germany, there were over 8000 landfill sites in use, while the number

\footnotetext{
${ }^{1}$ the liquid produced from the decomposition of waste within the landfill
} 
of currently operating landfill sites is below 300 (Hempen 2005). The EU Landfill Directive clearly promotes the diversion of waste from landfills towards products and materials recycling using a variety of measures (Council Directive 1999). The landfill restrictions introduced by the Article 5 of this Directive are very important, in particular the reduction in the amount of biodegradable waste going to landfill and the prohibition of landfilling for certain waste types. Since 1st June 2005, German landfills only accept biodegradable municipal waste that has been either incinerated or undergone mechanical and biological treatment while in Austria strict limits on the landfilling of organic wastes has also been introduced (Hempen 2005). Additionally, the UK Landfill Allowances and Trading Scheme Regulations (LATS) introduced in 2004, determines the percentage of certain waste type that are regarded as biodegradable municipal waste. These biodegradable percentage range from paper, card and vegetable oils (potentially $100 \%$ biodegradable) through to footwear, furniture and textiles ( $50 \%$ biodegradable) to batteries, glass and metal waste ( $0 \%$ biodegradable) (LATS 2004). This means that certain types of biodegradable materials such as leather, natural textiles, natural rubbers etc, which are extensively used by the footwear industry, will be soon required to be reused or recycled instead of directly disposed in landfill sites.

Footwear industry's response to this increasing problem of post-consumer shoe waste has been negligible. In fact, only one major shoe manufacturer, Nike ${ }^{\mathrm{TM}}$, has been taking measures to manage its waste. Nike's recycling programme "NikeGO-Places ${ }^{\mathrm{TM} " ~(f o r m e r l y ~ " R e u s e-A-S h o e ~}{ }^{\mathrm{TM}}$ ") is the only product take-back and recycling scheme currently established by a shoe manufacturer (Nike 
2006). This programme has been operating for over a decade in the United States and also just started operating in the UK, Australia and Japan. Their reuse and recycling programme involves a series of collection points in retail centres where people can deposit their worn-out and discarded athletic shoes. The shoes are then collected and taken to a central recycling facility where they are shredded, producing a material called "Nike-Grid"M", which can be used in surfacing of tennis and basketball playgrounds or running tracks. According to Nike (2006), since its inception in 1993, "Reuse-A-Shoe ${ }^{\mathrm{TM} "}$ programme has recycled more than 16 million pairs of worn-out and defective athletic shoes in total.

The limited activities in shoe recycling across the footwear industry highlights the paramount importance of investigating alternative approaches to footwear product recovery and recycling, as outlined in the remaining section of this paper.

\section{Footwear Product Recovery Methodology}

The footwear product recovery methodology aims to assist shoe designers, shoe manufacturers and recovery and recycling organisations in determining appropriate end-of-life scenarios for post-consumer shoes. The methodology enables the definition of alternative end-of-life scenarios to a level of detail that will allow economic, social-technical and environmental factors to be calculated, analysed and compared. The most appropriate EoL option recommended through the application of this methodology should minimise overall environmental impacts in a technically feasible way and at a reasonable cost. 
An integrated approach is therefore needed in order to incorporate all the potential decision criteria and take into consideration both quantitative and qualitative factors. The methodology provides a systematic way of considering all these factors in an attempt to identify optimal waste management options for post-consumer shoes. Figure 3 provides a visual representation of the phases included in the footwear product recovery methodology for post-consumer shoes.

Figure 4: Footwear Product Recovery Methodology

These phases starts with consideration of a set of input data regarding the type of the post-consumer shoe. In the first phase, the condition, value and type of shoe are assessed together with the construction methods and the materials used for each part of the shoe. Identification of potential product recovery scenarios and their related decision factors forms the next steps in the decision making process. Finally, quantitative (cost/benefits and environmental criteria) and qualitative (social-technical criteria) factors are calculated and an optimal product recovery scenario for a selected range of post-consumer shoes is proposed.-The four phases of this methodology are further described below.

\subsection{Product Characterisation}

The first phase of the methodology identifies the main characteristics of the footwear product. This step is needed in order to classify the product into its basic attributes and identify the crucial factors that determine the choice of a recovery option. This is performed in four steps, also referred to as screening 
levels. The first screening level determines basic characteristics of worn or discarded shoes such as the condition (e.g suitable or unsuitable for reuse), the value ( based on material content) and the type of the shoe (men's casual, sports trainers etc). This screening level is very important for the selection of a suitable product recovery option. For example, worn shoes in a relatively good condition can be refurbished and then reused while in the case of damaged or destroyed shoes, reuse is simply not considered. The second and third screening levels provide the necessary background information regarding the structure of the shoe and the construction methods that have been used to produce the shoe. The construction method, in particular, and the adhesives or stitching operations that have been applied to create a shoe can significantly influence the choice of appropriate destructive (shredding or granulating) or non-destructive (disassembly of upper and sole) recycling options. Finally, at the fourth screening level, materials used in shoe construction are classified according to their properties and then grouped into four major groups: leather, textiles, plastics and others. The major output of the first phase is a general categorisation of shoes based on their specific attributes and identification of important factors that influence the choice of an end-of-life management option.

\subsection{Recovery Scenario Selection}

In the second phase of the methodology, a waste management model constructed based on the output from the first phase. This waste management model for post-consumer shoes determines the different end-of-life management options, giving priority to recycling and reuse to minimise cost and environmental impacts. The output of such a model would identify potential 
treatments for post-consumer shoes depending on the shoe type. The shoe waste management model consists of the following end-of-life management options; reuse, recycling, energy recovery and disposal (Staikos et al. 2006). Reuse of post-consumer shoes is a possible option but there are few a variables that need to be considered such as the condition of the shoe at the end of its functional life, the collection and distribution system as well as the purpose of its reuse. Recycling involve the reprocessing of post-consumer shoes, parts or materials to be used either into the same product system (closed loop manufacture) or into different ones- In this approach, the waste is re-introduced back into the market through a series of destructive and nondestructive recycling processes. Energy recovery is another possible waste management option for post-consumer shoes which includes a number of established and emerging technologies such as incineration, gasification and pyrolysis. Finally, disposal of waste to landfills is currently the most common waste management option for post-consumer shoes.

\subsection{EoL Scenario Assessment}

In phase 3, decision factors that influence the EoL treatment options need to be identified. These factors should take into consideration both quantitative (environmental and economic) and qualitative (social-technical) criteria. Environmental criteria include a number of environmental impact category indicators i.e. global warming potential, human eco-toxicity etc. Economic criteria simply represent the costs and revenues for each end-of-life scenario (e.g. resale price of reused shoe, cost of landfilling etc). The list of socialtechnical criteria is almost endless and includes technical feasibility, market 
pressures, compliance with legislation etc. This list could be easily changed depending on the requirements of the analysis and the type of shoe under consideration.

Once the decision factors have been selected, these are then analysed for each recovery scenario in order to measure the impacts associated with all of the processes within the scenario. Information and data are collected and analysed in order to provide guidance on which is the optimal waste management solution for the selected type of shoe. The basic output of this phase is an assessment value for each recovery scenario based on social-technical, economic and environmental considerations. A number of decision making aid techniques have been utilised to analyse the decision criteria. The Analytic Hierarchy Process (AHP), however, has been used as the basic framework for simultaneous consideration of all these factors. AHP is a multi-criteria decision making (MCDM) method that has been used successfully in a variety of applications in different fields such as planning, resources allocation, optimisation and in general selecting the best alternative option (Vaidya et al. 2006). The AHP method decomposes a complex decision problem into a hierarchy and allows the consideration of both quantitative and qualitative (objective and subjective) factors in selecting the best alternative option (Saaty 1980). Economic criteria are calculated using Cost-Benefit Analysis (CBA) to identify cost and benefits for each recovery scenario while environmental impacts of various scenarios are calculated using a streamlined Life Cycle Assessment (LCA). Finally, social-technical criteria are calculated by applying the AHP method in a local scale. Figure 4 displays the framework for shoe 
recovery scenario assessment, including the different decision making methods that have been utilised.

Figure 5: Framework for Scenario Assessment

\subsection{Recovery Value Chain}

The final step in the methodology aims to identify a recovery value chain for the alternative scenarios and make sure that a market exists for such recovered products or materials. Once post-consumer shoes are collected, sorted and converted into a form that can be used by either the footwear industry or other industrial sectors, then it must compete with virgin materials both on price and performance. A sustainable footwear recycling application heavily depends on establishing a successful value shoe recovery chain. In this respect, a product recovery value chain can be described as the service of recovery and reuse of resources across a number of different sectors. Hence, this step of the footwear product recovery methodology is to identify suitable applications for each scenario. This can be achieved by establishing procedures that identify, within a broader context, value-added activities and benefits and seeking out the best recycling practices along different industrial sectors. Figure 6 presents a product recovery value chain for alternative end-of-life scenarios for shoes.

Figure 6: Recovery Value Chain for End-of-Life Scenarios for Shoes

However, not all post-consumer shoes can be considered to be suitable for recycling or reuse and, therefore, landfilling and even incineration without energy recovery of such materials could be considered as a practical option. 
Other issues that also need to be considered include the size and the value of the end market, the current and predicted buying trends as well as the range and price of competing materials and products. The basic output of this phase is a list of potential applications for shoe recycled materials.

\section{EoL Decision Support Tool for Footwear Products}

The determination of the most suitable (in environmental, economic and socialtechnical terms) manner in which to treat post-consumer shoe waste, as described in previous sections, is a complex process involving a wide range of materials, construction methods and recycling processes. Therefore, to support the implementation of the proposed footwear product recovery methodology, a prototype end-of-life (EoL) decision support tool has been developed. The prototype model was developed as a three-tier architecture as presented in Figure 7.

Figure 7: System Architecture of Prototype EoL Decision Support Tool

The presentation module acts as a user interface environment to receive and control user's input as well as to present the output. The database module provides a data repository in which information is stored and retrieved while the assessment module comprises the assessment/logic elements of the system that support the decision-making process.

\subsection{Presentation Module}

The user interface environment has been developed in Visual Basic for Applications (VBA) and integrated with a MS-Access environment. The main 
interface controls and integrates the major components of the proposed system and contains seven options to indicate the user selection. The main menu containing the EoL decision support system which includes most of the major functions of the tool are depicted in Figure 8. Each of these options leads to a further software module that supports a specific function within the system.

Figure 8: The Main Interface of the EoL Decision Support Tool

\subsection{Database Module}

The database module provides a back end database, comprising both data sets and the software system that manages and provides access to the data. This knowledge-based element supplies the required expertise for solving specific aspects of the problem domain. The core database of the model is constructed to provide essential information in order to generate product recovery and recycling scenarios. The core database is being developed on commercial software (MS-Access), and is still under development. The relational database model includes 16 tables in total. A pictorial representation of the database model is illustrated in Figure 9.

Figure 9: Database Model Structure

\subsection{Assessment Module}

The third module comprises the assessment element, the so-called logic of the system that supports the decision-making process. As previously described, each recovery scenario is assessed in terms of its environmental, economical, 
and social-technical criteria. These assessment processes are based on the various phases of the footwear product recovery methodology, as presented in Section 4.3.

\subsubsection{Calculate Environmental Criteria}

Environmental criteria for alternative end-of-life scenarios for shoes are calculated using a simplified Life Cycle Assessment (LCA) methodology. The Environmental Impact $(E I)$ score of each scenario is computed as follows (Wenzel et al. 1997):

$$
\begin{aligned}
& E l_{j}=\sum_{i=1}^{n} I C I i \\
& \text { where } \quad I C_{i}=\text { impact category indicator } i \\
& \qquad \mathrm{n}=\text { number of impact category indicators } \\
& \qquad \mathrm{j}=\text { number of end-of-life scenarios }
\end{aligned}
$$

The Life Cycle Inventory (LCI) data has been derived from a streamlined LCA study of average shoes, which was based on typical manufacturing data found in commercial databases. The LCI calculations and the Life Cycle Impact Assessment (LCIA) phase are conducted in SimaPro 7 LCA software using the EDIP (Environmental Design of Industrial Products) impact assessment method (Wenzel et al. 1997). The environmental impact score (Elj) of each scenario need to be normalised and expressed in unit-free numbers for consistency purposes. The normalised environmental impact score $\left(N E l_{j}\right)$ for each scenario is calculated as follows: 
i) calculate the reciprocal of each environmental impact score $\left(R E l_{j}\right)$

ii) divide the reciprocal of each environmental impact score $\left(R E l_{j}\right)$ by the sum of all reciprocal scores.

$$
\begin{aligned}
& N E I_{j}=\frac{R E I j}{\sum_{s} R E I j} \\
& \text { where } R E l_{j}=\frac{1}{E I j} \\
& \qquad E l_{j}=\text { environmental impact score of each scenario(s) }
\end{aligned}
$$

\subsubsection{Calculate Economic Criteria}

Economic values for each end-of-life scenario are calculated using the benefit to cost ratio approach. The benefit to cost ratio $(\mathrm{BCR})$ must be greater than or equal to 1 i.e. $B / C>1$, where $B$ is the benefit and $C$ is the cost of each alternative. The end-of-life economic value and benefit/cost ratio are calculated based on the following methods (Lee et al. 2001):

i) Reuse Benefit /Cost Ratio $\left(B C R_{R E}\right)$

The revenue of the reuse scenario $\left(B_{R E}\right)$ derived from the resale value of the shoe $\left(B_{\text {resale }}\right)$ while the costs $\left(C_{R E}\right)$ arising form collection costs $\left(C_{\text {collection }}\right)$, transportation costs $\left(\mathrm{C}_{\text {trans }}\right)$ and refurbishing costs $\left(\mathrm{C}_{\text {refurb }}\right)$. Therefore, the Reuse Benefit/Cost Ratio $\left(\mathrm{BCR}_{\mathrm{RE}}\right)$ can be obtained as follows:

$$
\mathrm{BCR}_{\mathrm{RE}}=\frac{\sum B_{R E}}{\sum C_{R E}}=\frac{B_{\text {resale }}}{C_{\text {collection }}+C_{\text {trans }}+C_{\text {refurb }}}
$$


ii) Recycling Benefit/Cost Ratio $\left(B C R_{R C}\right)$

The revenues of the recycling scenario $\left(B_{R C}\right)$ is a function of the weight of the recovered material $\left(B_{\text {weight }}\right)$ and the market value of the material $\left(B_{\text {value }}\right)$. The costs $\left(\mathrm{C}_{\mathrm{RC}}\right)$ arising form collection costs $\left(\mathrm{C}_{\text {collection }}\right)$, transportation costs $\left(\mathrm{C}_{\text {trans }}\right)$, separation costs $\left(\mathrm{C}_{\text {separation }}\right)$ and shredding costs $\left(\mathrm{C}_{\text {shred }}\right)$. Therefore, the Recycling Benefit/Cost Ratio $\left(\mathrm{BCR}_{\mathrm{RC}}\right)$ can be obtained as follows:

$$
\mathrm{BCR}_{\mathrm{RC}}=\frac{\sum B_{R C}}{\sum C_{R C}}=\frac{B_{\text {weight }} * B_{\text {value }}}{C_{\text {collection }}+C_{\text {trans }}+C_{\text {separaton }}+C_{\text {shred }}}
$$

\section{iii) Energy Recovery Benefit/Cost Ratio (BCR $\left.B_{E R}\right)$}

The revenues of the energy recovery scenario $\left(B_{E R}\right)$ is a function of the net energy produced $\left(B_{\text {energy }}\right)$ and the unit price of the produced energy $\left(B_{\text {price }}\right)$. The costs $\left(\mathrm{C}_{E R}\right)$ arising form collection costs $\left(\mathrm{C}_{\text {collection }}\right)$ and transportation costs $\left(\mathrm{C}_{\text {trans }}\right)$. Therefore, the Energy Recovery Benefit/Cost Ratio $\left(B C R_{E R}\right)$ can be obtained as follows:

$$
\mathrm{BCR}_{\mathrm{ER}}=\frac{\sum B_{E R}}{\sum C_{E R}}=\frac{B_{\text {energy }} * B_{\text {price }}}{C_{\text {collection }}+C_{\text {trans }}}
$$

\section{iv) Disposal Benefit/Cost Ratio (BCR $D S)$}

There are no projected revenues in the disposal scenario $\left(\mathrm{B}_{D S}\right)$. The costs $\left(\mathrm{C}_{D S}\right)$ arise from transportation costs and landfilling costs. Landfilling cost is a function 
of the weight of the shoe and the actual cost of landfilling per tonne of material. Therefore, the Disposal Benefit/Cost Ratio $\left(\mathrm{BCR}_{\mathrm{ER}}\right)$, is always zero:

$$
\mathrm{BCR}_{\mathrm{DS}}=\frac{\sum B_{D S}}{\sum C_{D S}}=0
$$

The benefit to cost ratio $\left(B C R_{j}\right)$ for each end-of-life scenario is then normalised for consistency purposes. The Normalised Benefit/Cost Ratio (NBCR $)_{j}$ is calculated by dividing each Benefit/Cost Ratio by the sum of all Benefit/Cost ratios as given in Eq. (1), (2), (3) and (4):

$$
\begin{aligned}
& N B C R_{j}=\frac{\mathrm{BCRj}}{\sum_{j} \mathrm{BCRj}} \\
& \text { where } \\
& \qquad B C R_{s}=\text { Benefit/Cost Ratio for each scenario } \\
& \\
& \quad j=\text { number of waste management scenarios }
\end{aligned}
$$

\subsubsection{Calculate Social-Technical Criteria}

Social-technical criteria (e.g. technical feasibility, public opinion, market pressures, compliance with legislation) are calculated by using the AHP method. The same AHP steps are performed as described in Section 4.3: structuring the problem into a hierarchy, making a series of pairwise 
comparisons to identify the weight of each criterion, calculate criteria weights and, finally, synthesize the priorities into a composite weight. The final result is a score (composite weight) for each alternative end-of-life scenario with respect to each social-technical criterion. Figure 11 shows graphically the composite weight of five alternative end-of-life scenarios, namely shredding the shoe as a whole (Recycling Scenario 1), disassembly of upper and sole before shredding to gain higher quality of recycled material (Recycling Scenario 2), together with Reuse, Incineration and Disposal scenarios for a selected type of shoe (men's casual shoe).

Figure 10: Calculation of Social-Technical Criteria

The results presented in Figure 10 indicate that Recycling Scenario 1 (shredding the shoe as a whole) is the most preferable option with respect to the social-technical criteria for a men's casual shoe. However, it should be mentioned that the weight value of the social-technical criteria rely less on numbers and statistics but more on interviews, questionnaires, subjective reports and case studies. In this respect, the social-technical criteria and their weights can be easily changed by the user depending on the requirements of the analysis.

\subsubsection{Synthesis of Overall Results}

The final step of the assessment process, as part of the AHP method, is to synthesize the overall results in order to produce a global priority vector for each end-of-life scenario. The global priority vector indicates the preference (or the composite weight) of each alternative option. Figure 11 shows graphically 
the preference of the five alternative end-of-life scenarios, as previously presented in Section 5.3.3, for a men's casual shoe.

\section{Figure 11: Final Output of EoL Decision Support Tool}

The final output of the analysis, as presented in Figure 11, indicate that Recycling Scenario 2 (disassembly of shoe) is the most preferable option for a men's casual shoe, whereas Disposal Scenario (landfilling) is the least. It should be mentioned that this demonstration of the AHP method is only an example of how this multi-criteria decision making technique could be used by the EoL decision support tool in order to identify optimal solutions.

\section{Conclusion}

The large amount of post-consumer shoe waste produced every year, the legislative pressures to divert waste from landfills as well as the hidden value of recyclable materials in post-consumer shoes have led to the development of an end-of-life decision support tool and methodology to support the determination of the most suitable treatment option for post-consumer shoes. The key to success in establishing product recovery and recycling procedures is to identify economically justified end-of-life options with the lowest possible risk to the environment. Additionally, the new innovative product recovery value chains must be created that recognize value and benefits within a broader context and seeking out for best recycling practices along the same or different industrial sectors. The most appropriate end-of-life product recovery option, however, often depends on the nature of the product itself and largely depends on 
whether the objective is to minimise environmental impacts or maximise economic benefits. Therefore, there is clearly a need to identify a systematic way of considering all these factors in an attempt to reach decisions that are environmentally, technically and economically justified.

This paper describes a four-step methodology for reaching end-of-life management decisions for footwear products. This methodology could be used to find optimal product recovery and recycling procedures for footwear products based on the combination of material content, recycling feasibility, recycling application and cost, social-technical and environmental considerations. However, the identification of optimal product recovery and recycling practices for every footwear material group can be a very complex task due to the wide range of materials and processes involved in footwear production. This creates the need for developing knowledge-based approaches that can provide understanding of the relationship and their trade offs among various end-of-life options. Based on this methodology, an end-of-life decision support tool has been developed to facilitate the process of decision making. Design and specification of the prototype EoL decision support tool are provided in this paper. This tool could be used by a number of end users including footwear designers, material suppliers, shoe manufacturers, as well as recycling and product recovery organisations.

One of the primary conclusions of the research on the application of product recovery in the footwear industry has been the paramount importance of the role of footwear designers to promote sustainable design practices along the footwear industry. In this context, the footwear recovery methodology and tool 
presented in this paper can be used to support the material selection based on the recyclability factors of footwear materials while enabling other design optimisation activities to make the reuse and recycling of footwear materials, components and parts easier, thus reducing the amount of waste disposed into landfills.

\section{References}

American Apparel and Footwear Association (AAfA), US Shoe Stats 2005, Available online at: https://www.apparelandfootwear.org/UserFiles/File/Statistics/ShoeStats200 5.pdf (accessed 04 August 2006).

Barry M., LMB Education, Personal Interview, (17 July 2006).

CBI, EU Market Survey 2004: Footwear, Centre for the Promotion of Imports form Developing Countries (CBI), 2004.

Clarks Ltd, Manual of Shoe Making, 1976, (Clarks Training Department: Somerset).

Council Directive 99/31/EC of 26 April 1999 on the Landfill of Waste. OJ L 182.

Environmental Resources Management (ERM), Textile Recycling, Fact sheet researched and written for the Department of Trade and Industry, 2002, Available online at: http://www.wasteonline.org.uk/resources/InformationSheets/Textiles.htm (accessed 13 February 2006).

European Commission (EC), Footwear Statistics, Available online at: http://europa.eu.int/comm/enterprise/footwear/statistics.htm (accessed 04 August 2006).

Harvey, A., Footwear Materials and Process Technology, 1982, (Lasra Publications: New Zealand).

Hempen S., Status and Trends of Residual Waste Treatment in Germany, in Proceedings of Conference: The Future of Waste Management in Europe, 2005. 
Landfill Allowances and Trading Scheme (LATS) Regulations, 2004, Statutory Instrument 2004 No 3212, Department of Environment, Food and Rural Affairs.

Lee S.G., Lye W. and Khoo M.K., A Multi-Objective Methodology for Evaluating Product End-of-Life Options and Disassembly, International Journal of Advanced Manufacturing Technology, 2001, 18, pp. 148-156.

NIKE Reuse-A-Shoe, Available online at: http://www.nike.com (accessed at 15 June 2006).

Rossi, W.A., The Complete Footwear Dictionary (2nd Edition), 2000 (Malabar: Kreiger Publishing Co.).

Saaty T.L., The Analytical Hierarchy Process: Planning, Priority Setting, Resource Allocation, 1980, (McGraw-Hill: New York).

SATRA, Footwear Market Predictions: Forecasts for Global Footwear Trading to 2009, 2003, (SATRA Technology Centre: Kettering).

Staikos T., Heath R, Haworth B. and Rahimifard S., End-of-Life Management of Shoes and the Role of Biodegradable Materials, in Proceedings of 13th CIRP International Conference on Life Cycle Engineering, 2006, pp. 497502.

Vaidya O. and Kumar S., Analytical Hierarchy Process: An Overview of Applications, European Journal of Operational Research, 2006, 169, 1-29.

Weib M., Recycling alter Schuhe, Schuh-Technik, 1999, May-June, pp. 26-29.

Wenzel H, Hauschild M and Alting L, Environmental Assessment of Products: Volume 1: Methodology, Tools and Case Studies in Product Development, 1997, (Chapman \& Hall: London).

Wilson M., Abbot S. and Tame R., Moulded-On Solings. 1997, Modern Shoemaking: No. 53, (SATRA Technology Centre: Kettering).

Woolridge A., Ward G., Phillips P., Collins M. and Gandy S., Life Cycle Assessment for Reuse/Recycling of Donated Waste Textiles Compared to Use of Virgin Materials: An UK Energy Perspective, Resources, Conservation and Recycling, 2006, 46, pp. 94-103. 
World Footwear, The Future of PU Solling, World Footwear, 2005, January/February, pp.18-20.

World Footwear, Polyurethane: Today and Tomorrow, World Footwear, 2007, January/February, pp.27-31. 

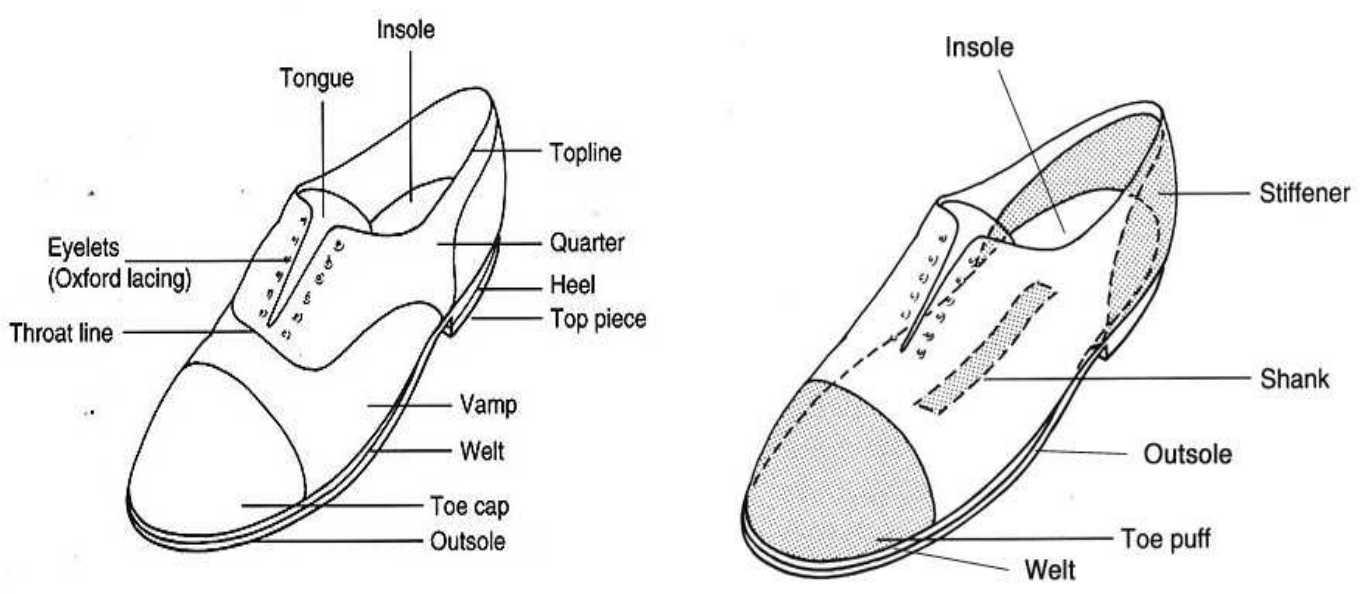


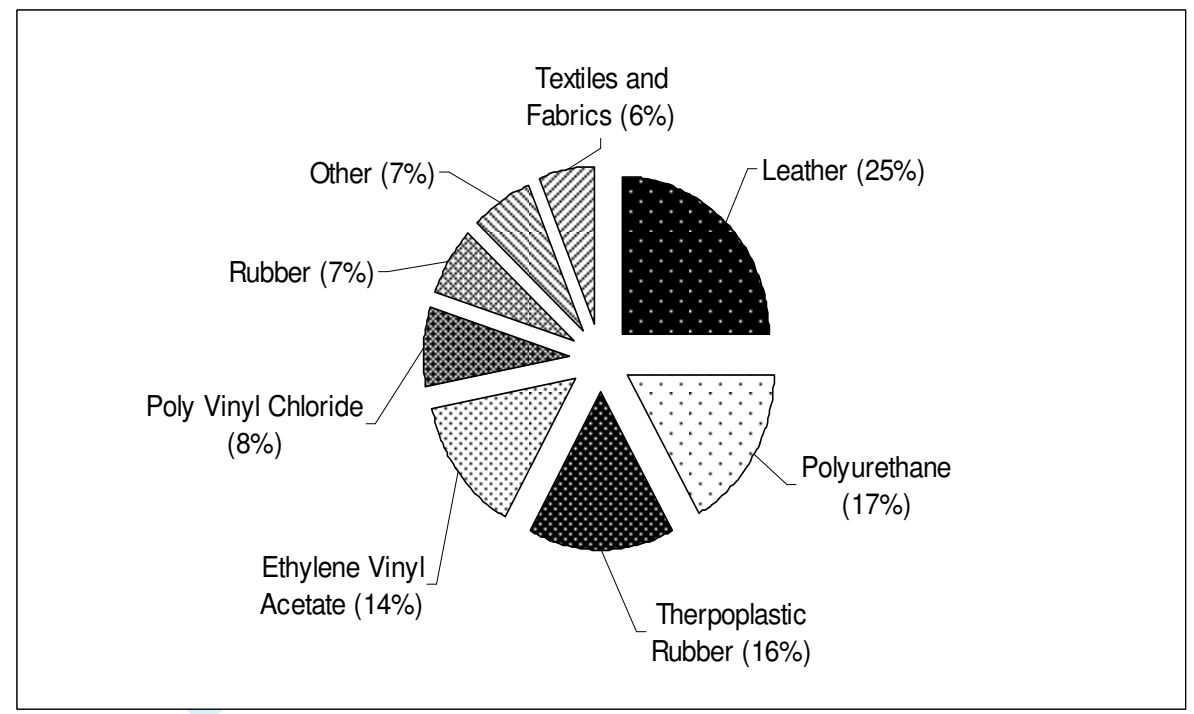




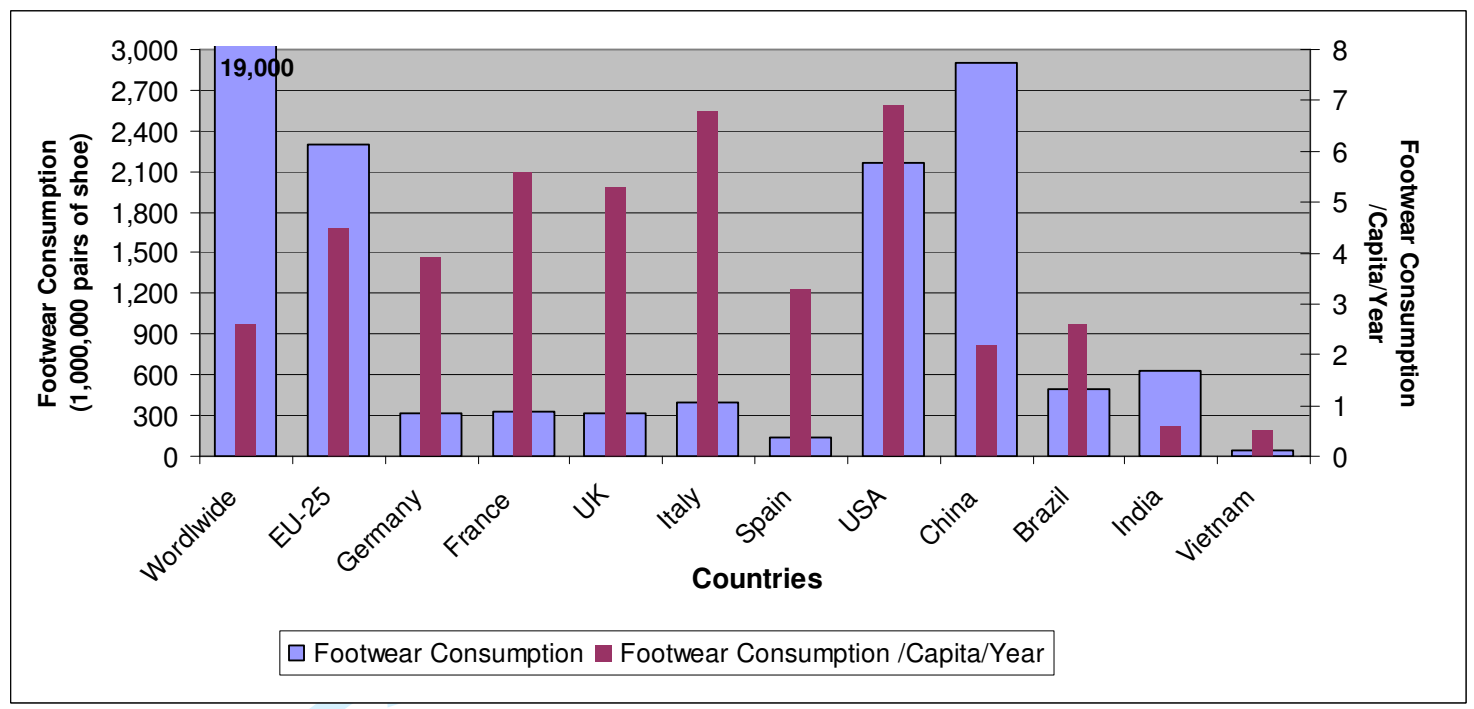




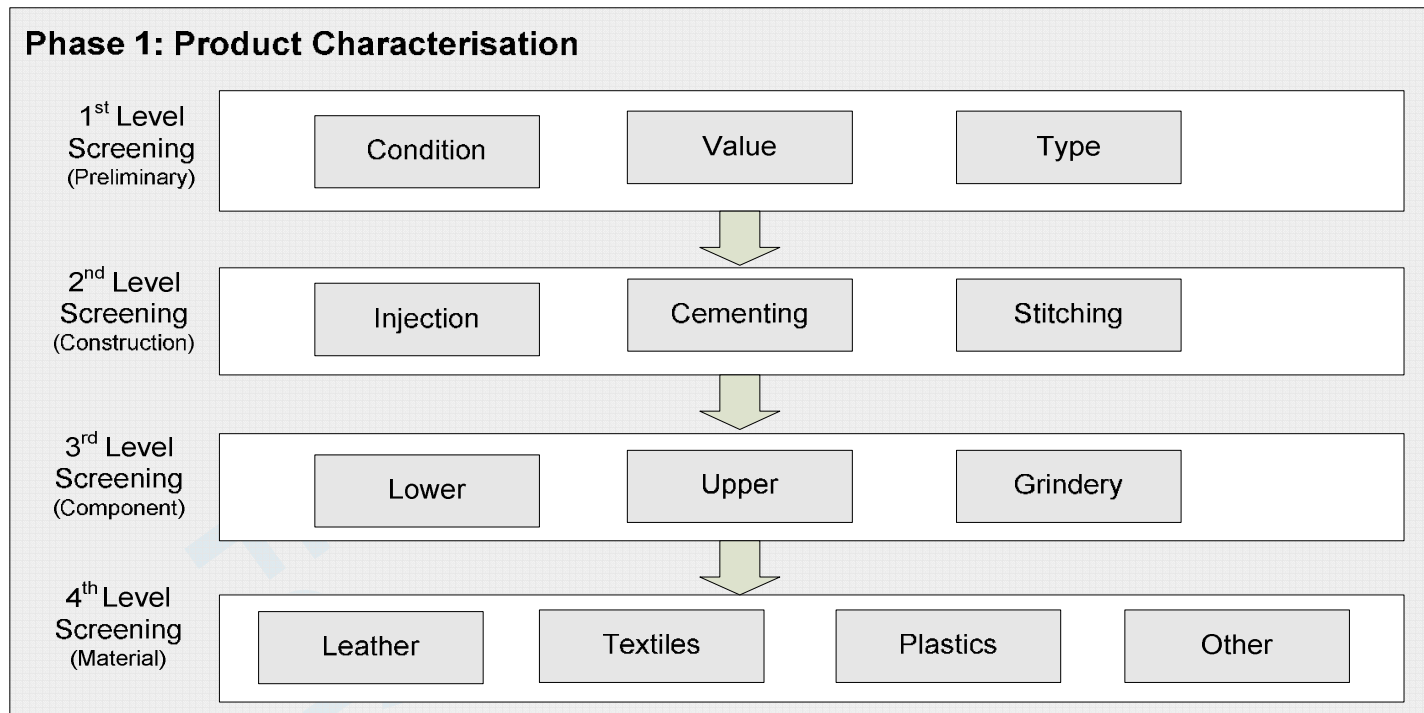

Phase 2: Recovery Scenario Selection

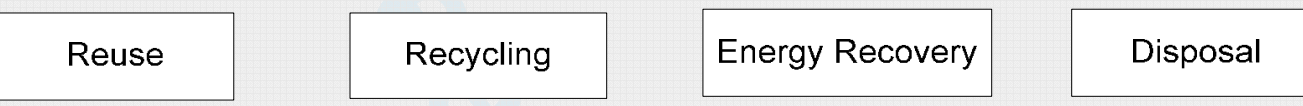

\section{Phase 3: EoL Scenario Assessment}
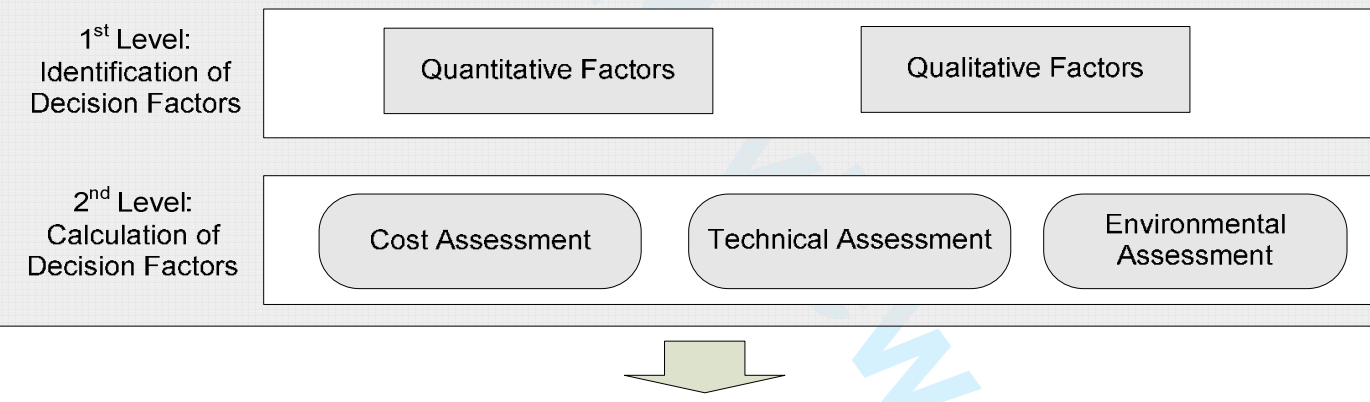

Phase 4: Recovery Value Chain Identification

Footwear Product
System
Other Product Systems


Shoe Materials and Manufacturing Characteristics

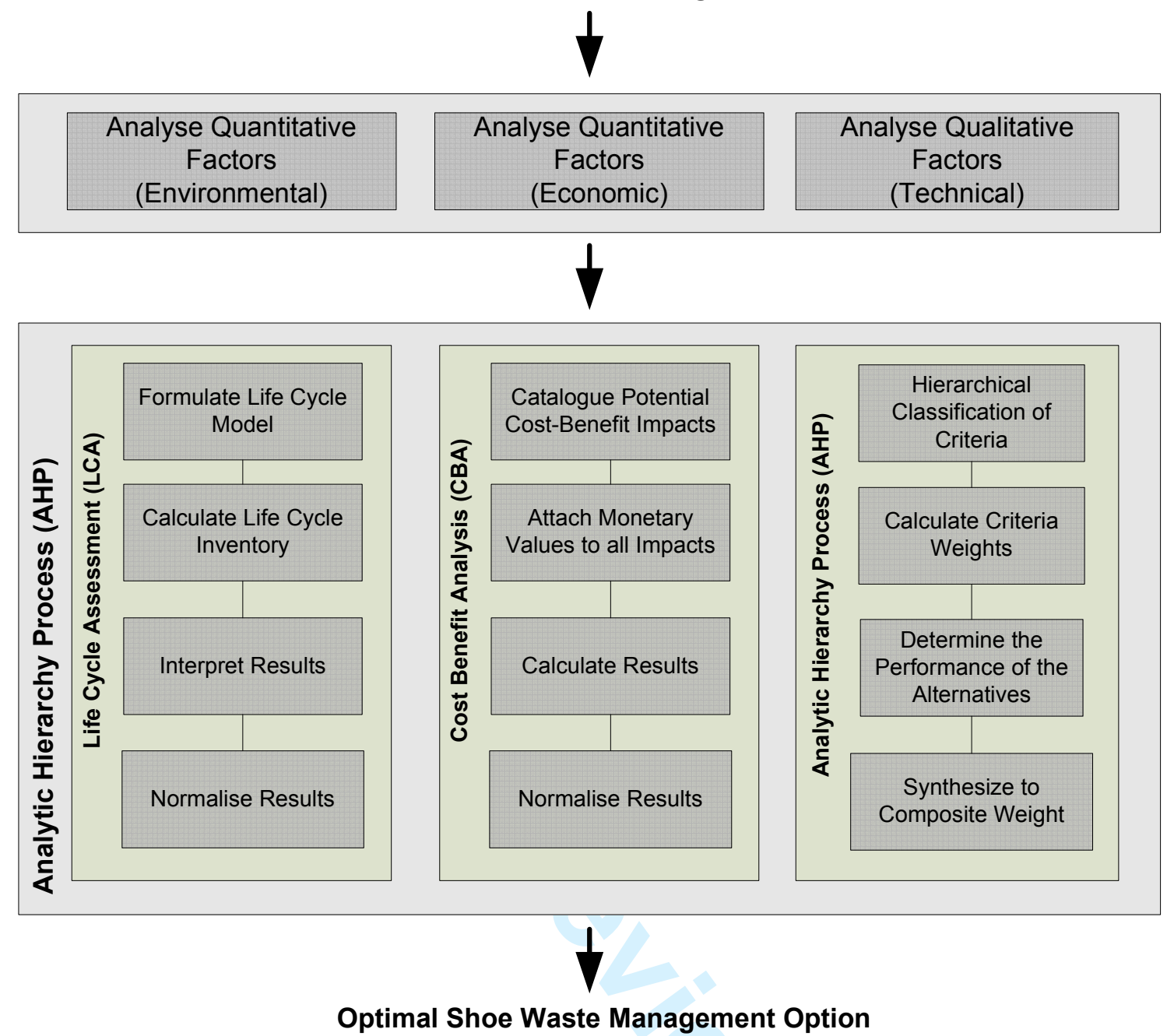




\section{Value-Added Activities}

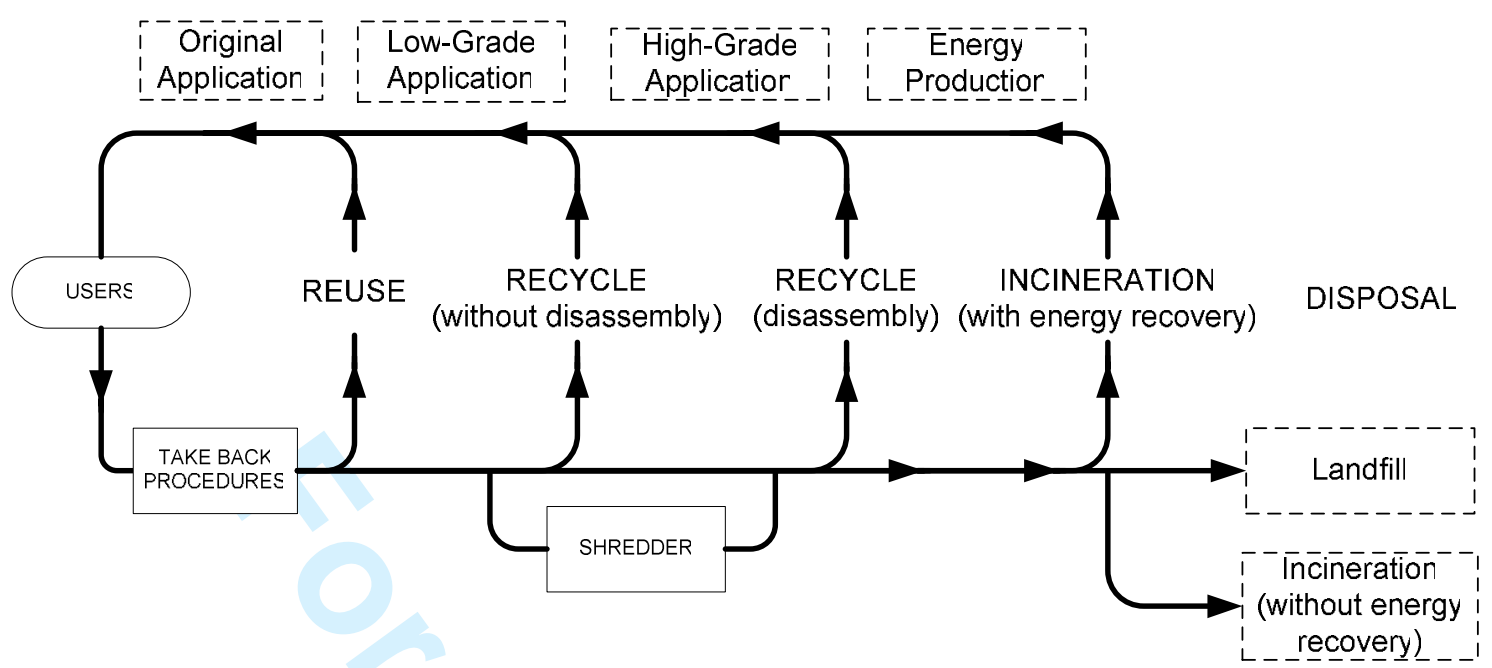

Non Value-Added Activities 


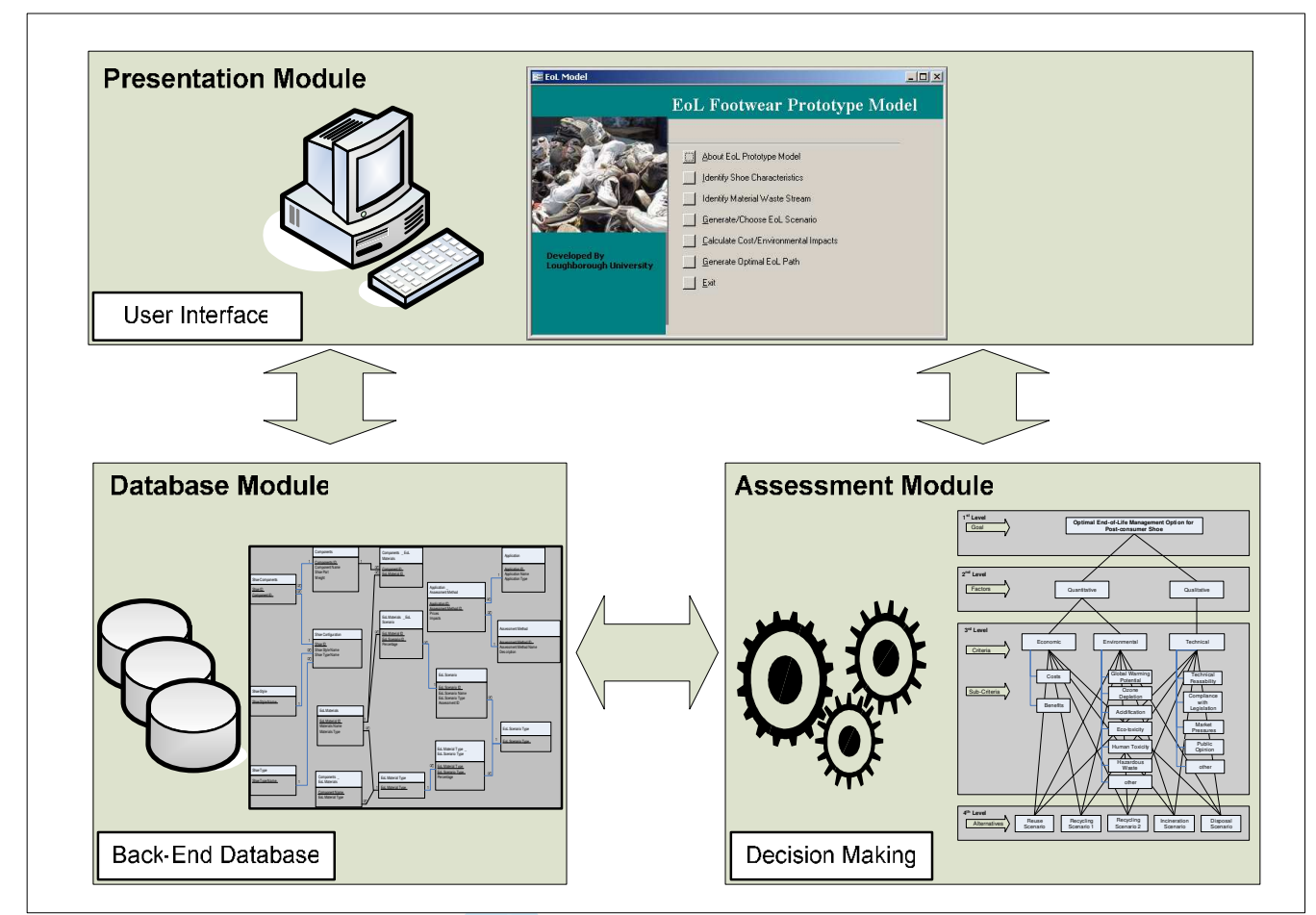




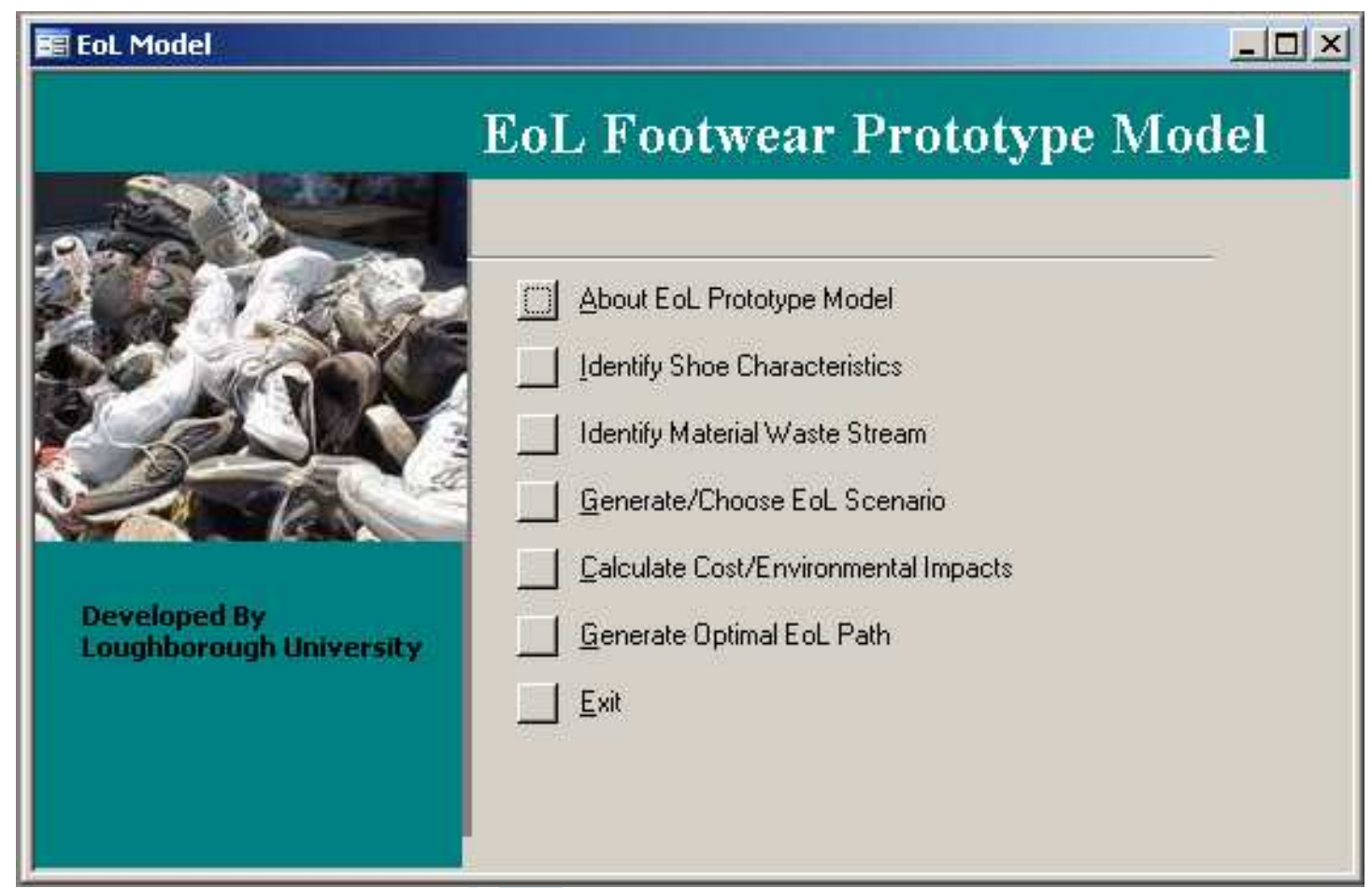




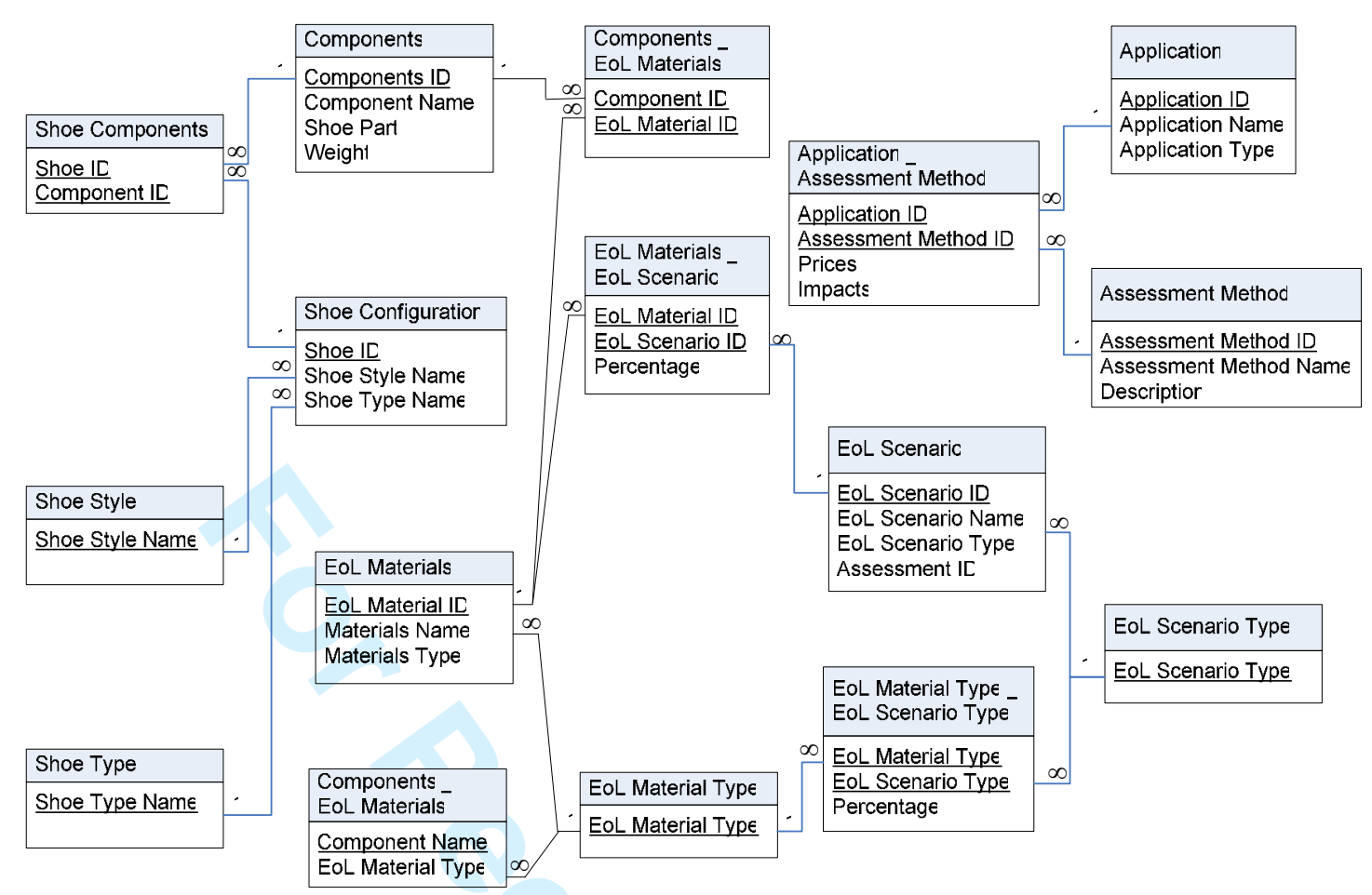




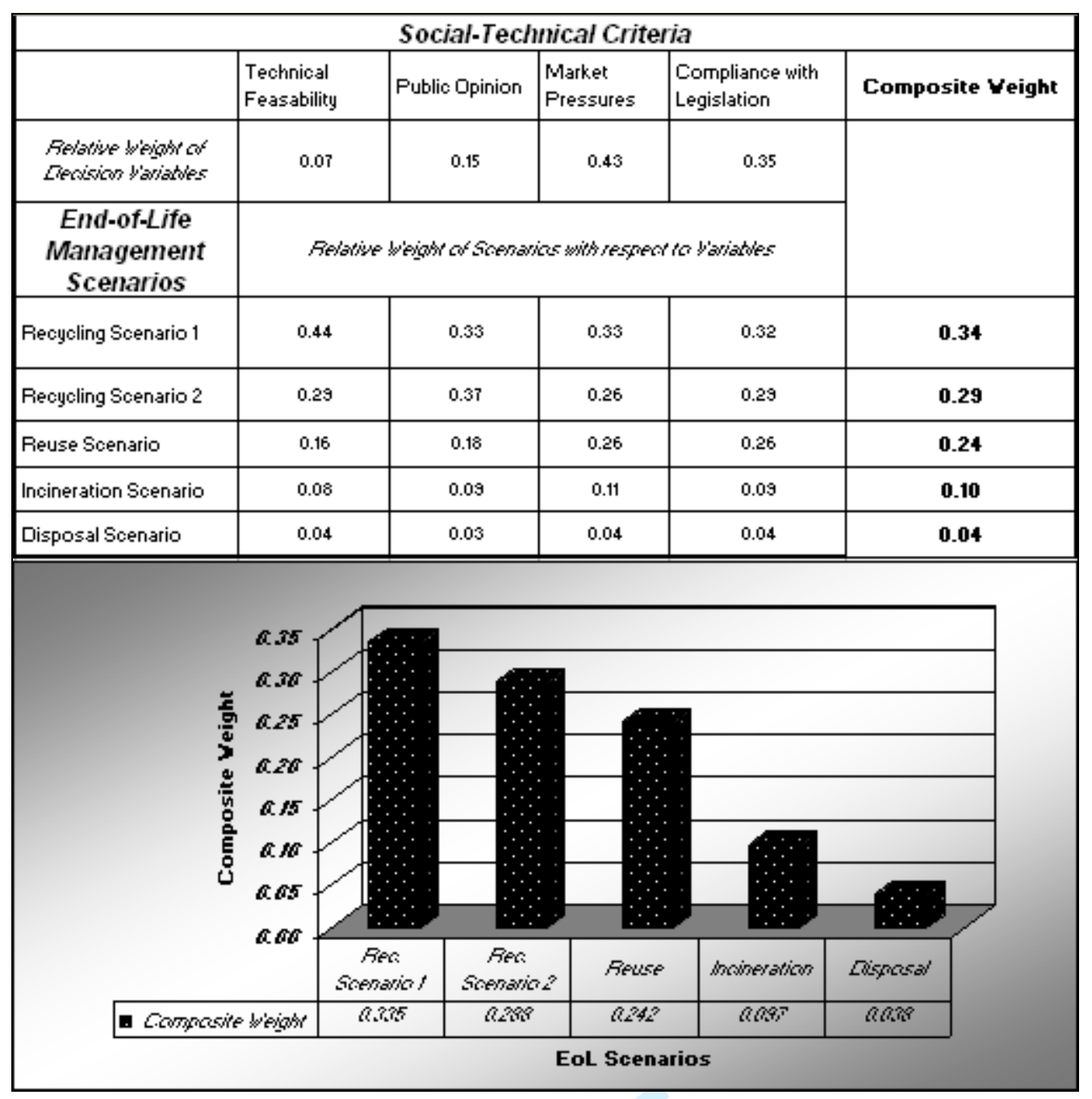




\begin{tabular}{|c|c|c|c|c|}
\hline \multicolumn{5}{|c|}{ SYNTHESIS OF OYERALL RESULTS } \\
\hline & \multicolumn{2}{|c|}{ Quantiotire Fartoss } & \multirow{2}{*}{ 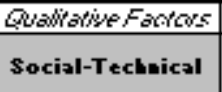 } & \multirow{4}{*}{$\begin{array}{c}\text { Global Priority } \\
\text { Yector }\end{array}$} \\
\hline & Emironental & Econonic & & \\
\hline & & & & \\
\hline & 0.56 & 0.32 & 0.12 & \\
\hline Recycling Scenario 1 & 0.32 & 0.27 & 0.34 & 0.32 \\
\hline Recycling Scenario 2 & 0.31 & 0.28 & 0.29 & 0.37 \\
\hline Reuse Scenario & 0.31 & 0.32 & 0.24 & 0.25 \\
\hline Incineration Scenario & 0.03 & 0.13 & 0.10 & 0.04 \\
\hline Disposal Scenario & 0.03 & 0.00 & 0.04 & 0.02 \\
\hline
\end{tabular}

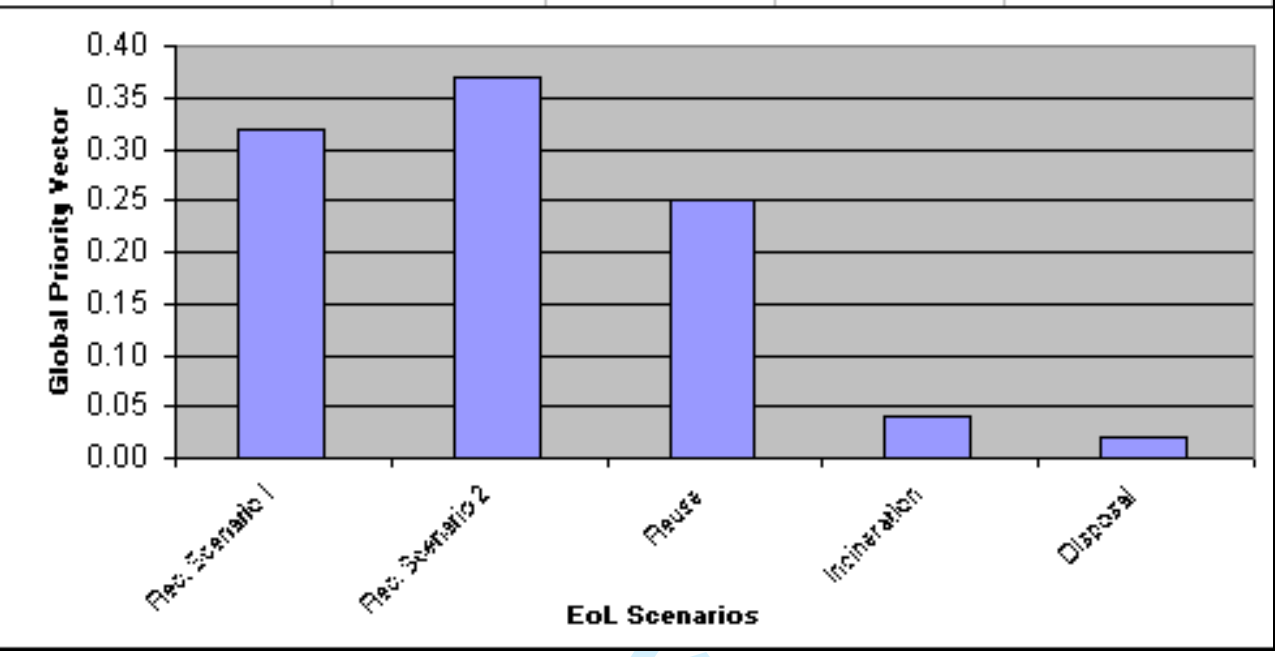




\begin{tabular}{|c|c|c|c|c|c|c|c|}
\hline Types of $\mathrm{s}$ & loes & $\begin{array}{l}\text { Men's } \\
\text { Formal }\end{array}$ & $\begin{array}{l}\text { Men's } \\
\text { Casual }\end{array}$ & $\begin{array}{l}\text { Women's } \\
\text { Court }\end{array}$ & $\begin{array}{l}\text { Women's } \\
\text { Fashion }\end{array}$ & Children's & $\begin{array}{l}\text { Adult } \\
\text { Sports } \\
\text { Trainer }\end{array}$ \\
\hline & & 1 & 2 & 3 & 4 & 5 & 6 \\
\hline Upper Part & & & & & & & \\
\hline Leather & & $\checkmark$ & $\checkmark$ & $\checkmark$ & $\checkmark$ & $\checkmark$ & \\
\hline & Canvas & & $\checkmark$ & & $\checkmark$ & $\checkmark$ & \\
\hline Synthetic & Polyurethane & & $\checkmark$ & & $\checkmark$ & & $\checkmark$ \\
\hline Materials & PVC & & $\checkmark$ & & $\checkmark$ & & $\checkmark$ \\
\hline Lower Part & (Soles) & & & & & & \\
\hline Leather & & $\checkmark$ & & & & & \\
\hline Leather/Pc & lymer & $\checkmark$ & $\checkmark$ & $\checkmark$ & $\checkmark$ & & \\
\hline Vulcanise & ubber & & $\checkmark$ & & $r$ & & \\
\hline TPR & & & $\checkmark$ & & $\checkmark$ & $\checkmark$ & \\
\hline Polyuretha & ne's & & $\checkmark$ & & $\checkmark$ & $\checkmark$ & $\checkmark$ \\
\hline TPU & & & $\checkmark$ & & $\checkmark$ & $\checkmark$ & $\checkmark$ \\
\hline EVA & & & $\bar{v}$ & & $\checkmark$ & & $\checkmark$ \\
\hline Grindery I & ems & & & & & & \\
\hline Shanks & & $\checkmark$ & & $\checkmark$ & & & \\
\hline Nails & & $\checkmark$ & & $\checkmark$ & & & \\
\hline Eyelets & & $\checkmark$ & $\checkmark$ & & $\checkmark$ & $\checkmark$ & \\
\hline Laces & & $\checkmark$ & $\checkmark$ & & $\checkmark$ & & $\checkmark$ \\
\hline Threads & & $\checkmark$ & $\checkmark$ & $\checkmark$ & $\checkmark$ & $\checkmark$ & $\checkmark$ \\
\hline Velcro \& C & atches & & & & & $\checkmark$ & \\
\hline $\begin{array}{l}\text { Textile Bac } \\
\text { \& Linings }\end{array}$ & kers & $\checkmark$ & $\checkmark$ & $\checkmark$ & $\checkmark$ & $\checkmark$ & $\checkmark$ \\
\hline Foams- $(\mathrm{P}$ & dding) & $\checkmark$ & $\checkmark$ & $\checkmark$ & & $\checkmark$ & $\checkmark$ \\
\hline
\end{tabular}




\begin{tabular}{l|l|l|l|l|l|l}
\hline Heal Backing supports. & $\checkmark$ & $\checkmark$ & $\checkmark$ & $\checkmark$ & $\checkmark$ & $\checkmark$ \\
\hline Toe cap reinforcement. & $\checkmark$ & $\checkmark$ & $\checkmark$ & $\checkmark$ & $\checkmark$ & $\checkmark$ \\
\hline Heals- (Ladies/Men's) & $\checkmark$ & $\checkmark$ & $\checkmark$ & $\checkmark$ & & \\
\hline \hline
\end{tabular}




\begin{tabular}{l|c}
\hline \hline Soling Materials & Percentage (\%wt) \\
\hline Resin Rubber & 19 \\
\hline PVC and blends & 15 \\
\hline Thermoplastic Rubber (TR) & 8 \\
\hline Direct Vulcanised (DV) Rubber & 8 \\
\hline Direct Injection Moulded (DIM) PVC and blends & 7 \\
\hline Leather & 7 \\
\hline Micro Ethylene Vinyl Acetate (EVA)/ Rubber & 7 \\
\hline Polyurethane (PU) & 5 \\
\hline Other (wood, cork, textile etc) & 4 \\
\hline Vulcanised Rubber & \\
\hline \hline
\end{tabular}

